\title{
Pengaruh Abu Vulkanis Gunung Agung dan Pupuk Kompos terhadap Beberapa Sifat Tanah dan Hasil Kacang Tunggak (Vigna unguiculata (L.) Walp.)
}

\author{
I WAYAN NARKA*), I NYOMAN DIBIA, DAN I WAYAN DANA ATMAJA \\ Program Studi Agroekoteknologi Fakultas Pertanian Universitas Udayana \\ Jl. P.B. Sudirman, Denpasar, Bali 80232 \\ ${ }^{*}$ E-mail: wayannarka61@gmail.com
}

\begin{abstract}
The Effect of the Mount Agung Volcanic Ash and Compost on Soil Properties and Yield of Tunggak Nuts (Vigna unguiculata (L.) Walp). The purpose of this study was to determine the effect of giving volcanic ash and compost as a soil amendment. The design used was a factorial randomized block design. The volcanic ash factor consisted of 3 levels: $\mathrm{A} 0=$ no volcanic ash, $\mathrm{A} 1=15 \%$ volcanic ash and $\mathrm{A} 2=30 \%$ volcanic ash. The compost factor consisted of 3 levels: $\mathrm{K} 0=$ without compost, $\mathrm{K} 1=10$ tons of compost ha ${ }^{-1}$, and $\mathrm{K} 2=20$ tons of compost ha- ${ }^{-1}$. The combination treatments was repeated 3 times so that there were 27 observation units. Several parameters of soil properties and yield of tunggak nuts were studied to determine the effect of volcanic ash and compost as soil amendments. The results showed that the interaction between the treatment of volcanic ash and compost on the soil and plants was not significant, while the single treatment of compost had a significant effect on the growth and yield of tunggak nuts. The treatment of volcanic ash has not shown a significant effect, both on soil and on plant growth and yield.
\end{abstract}

Keywords: volcanic ash, compost, soil properties, tunggak nuts

\section{PENDAHULUAN}

Material padat dalam bentuk debu yang disemburkan oleh gunung api pada saat meletus dinamakan abu vulkanis. Abu vulkanis biasanya terdiri gelas vulkanis, labrodonit, augit, dan sedikit bitounit, hiperstin, hornblende, dan opak. Selain mineral opak, semua mineral tersebut mudah lapuk dan melepaskan banyak hara ke dalam tanah (Anda et al., 2012). Abu vulkanik yang menutupi permukaan tanah dapat memberikan proses peremajaan dan peningkatan kesuburan tanah (Hasanah et al., 2015).

Material erupsi Gunung Agung menyebabkan kerusakan lahan sehingga 


\section{WAYAN NARKA et al. Pengaruh Abu Vulkanis Gunung Agung dan Pupuk Kompos...}

sulit untuk dipulihkan menjadi lahan usahatani produktif dalam waktu singkat, tetapi setelah beberapa waktu kemudian, dapat memberikan berkah karena menambah mineral mudah lapuk yang banyak mengandung unsur bermanfaat bagi tanaman. Berapa lama waktu yang dibutuhkan untuk terjadinya pelapukan sehingga tersedia bagi tanaman belum diketahui dengan pasti. Penelitian mengenai pengaruh abu vulkanis Gunung Agung terhadap tanah dan tanaman belum banyak dilakukan. Penelitian ini merupakan penelitian awal untuk mengetahui pengaruh abu vulkanis Gunung Agung terhadap tanah dan tanaman. Berdasarkan literatur dan hasil penelitian mengenai abu vulkanis beberapa gunung berapi di Jawa adalah abu vulkanis dapat memperbaiki sifat tanah dan pertumbuhan tanaman

Kompas.com 6 Oktober 2017 menampilkan berita letusan abu Gunung Agung dapat menghasilkan tanah tersubur di dunia. Abu vulkanis mengandung mineral primer yang banyak mengandung unsur hara. Dengan berjalannya waktu, terjadi proses pelapukan, abu akan mengeluarkan unsur hara dan area permukaan butiran akan membesar dan mampu menampung lebih banyak nutrient dan air (Kompas.com., 2017).
Abu vulkanik merupakan material yang baru keluar (recent material) sehingga belum dapat menyumbangkan unsur hara bagi tanaman karena belum mengalami proses pelapukan yang sempurna (Nurlaeny et al.,2012). Bahan organik dapat mempercepat proses pelapukan. Asam humat-fulvat merupakan fraksi bahan organik yang mempunyai peranan penting dalam reaksi kimia di dalam tanah. Melalui pembentukan khelat logam-organik, asam-asam organik akan melarutkan mineral-mineral primer dan sekunder yang ada di dalam media tanam dan selanjutnya akan menjadi tersedia bagi tanaman (Foy et al., 1978).

Kombinasi bahan organik berupa pupuk kompos dengan abu vulkanis Gunung Agung diharapkan dapat memperbaiki kesuburan tanah dan pertumbuhan tanaman. Selain mempercepat pelapukan abu vulkanis, bahan organik berupa kompos juga memperbaiki sifat fisik, sifat kimia dan sifat biologi tanah. Hipotesis penelitian ini adalah pemberian abu vulkanis Gunung Agung dan pupuk kompos dapat memperbaiki sifat tanah dan pertumbuhan tanaman kacang tunggak.

\section{BAHAN DAN METODE}


Penelitian dilakukan di rumah kaca kebun percobaan Fakultas Pertanian Universitas Udayana. Masing-masing pot diisi dengan $10 \mathrm{~kg}$ tanah, kemudian diberikan perlakuan penambahan abu vulkanis dan pupuk kompos. Bentuk percobaan yang digunakan pada penelitian ini adalah bentuk factorial dengan rancangan dasar Rancangan Acak Kelompok (RAK). Dua faktor yang diuji adalah: penambahan abu vulkanis dan penambahan pupuk kompos. Perlakuan penambahan abu vulkanis terdiri dari 3 taraf perlakuan, yaitu: tanpa abu vulkanis (A0), $10 \%$ abu vulkanis (A1), dan $20 \%$ abu vulkanis (A2). Perlakuan pupuk kompos diberikan dalam 3 taraf yaitu: tanpa pupuk kompos (K0), 10 ton/ha pupuk kompos (K1), 20 ton/ha pupuk kompos (K2). Kombinasi dari dua faktor yang diuji menghasilkan 9 kombinasi perlakuan. Masing-masing perlakuan kombinasi diulang sebanyak 3 kali sehingga terdapat 27 pot percobaan. Bahan yang digunakan dalam penelitian ini meliputi: abu vulkanis, pupuk kompos, benih kacang tunggak, tanah inceptisol dan zat-zat kimia untuk analisis tanah. Alat-alat yang digunakan meliputi: ember untuk pot penanaman, ayakan untuk ngayak tanah, alat penyiraman, oven, timbangan, dan alat-alat lain untuk analisis tanah

Parameter yang diamati meliputi parameter tanah dan tanaman. Parameter tanah yang diamati: bulk density tanah, Corganik, kadar nitrogen $(\mathrm{N})$, fosfor $(\mathrm{P})$, dan kalium (K), sedangkan parameter hasil tanaman kacang tunggak meliputi: tinggi tanaman, berat buah kering oven, berat biji kering oven dan berat brangkasan kering oven.

Metode analisis tanah yang digunakan adalah: penetapan kadar $\mathrm{N}$ tanah dengan metode Kjeldahl, $\mathrm{P}$ dan $\mathrm{K}$ dengan metode Bray 1, C-organik dengan metode Walkey \& Black, dan, bulk density dengan metode ring sampel. Data yang diperoleh dianalisis secara statistic sesuai dengan rancangan yang digunakan. Jika hasil sidik ragam menunjukkan signifikan, selanjutnya dilakukan analisis BNT $5 \%$

\section{HASIL DAN PEMBAHASAN}

Berdasarkan hasil analisis statistika tidak ditemukan interaksi antara pemberian abu vulkanis dengan pupuk kompos, sehingga pembahasan dilakukan secara tunggal pada perlakuan abu vulkanis atau pupuk kompos. Pemberian abu vulkanis tidak berpengaruh nyata terhadap berat volume tanah hanya terdapat 


\section{WAYAN NARKA et al. Pengaruh Abu Vulkanis Gunung Agung dan Pupuk Kompos...}

kecenderungan peningkatan, sedangkan pemberian pupuk kompos berpengaruh nyata (Tabel 1). Berat volume terendah ditemukan pada pemberian pupuk kompos 20 ton/ha. Menurunnya berat volume tanah akibat penambahan pupuk kompos diduga disebabkan karena pupuk kompos memperbaiki struktur tanah. Struktur tanah yang lebih baik akan menyebabkan tanah menjadi lebih gembur dan selanjutnya akan menyebabkan berat volume tanah menjadi lebih rendah. Penelitian mengenai pemberian pupuk organic terhadap sifat fisik tanah telah dilaporkan bahwa pemberian 30 ton pupuk kandang sapi dapat menurunkan berat volume tanah, porositas dan permeabilitas tanah (Lawenga et al., 2015).

Kadar C-organik tanah menunjukkkan peningkatan secara nyata akibat adanya pemberian pupuk kompos. Peningkatan ini disebabkan karena kandungan C-organic pupuk kompos yang digunakan cukup besar yaitu 12,85\% dan dosis yang diberikan cukup tinggi sampai
20 ton/ha. Nurlaeny et al. (2012) meneliti pengaruh kombinasi abu vulkanik Merapi, pupuk kandang sapi dan tanah mineral terhadap sifat fisiko-kimia media tanam dengan indikator pertumbuhan tanaman jagung (Zea mays L.). Hasil penelitian menunjukkan bahwa berbagai kombinasi media tanam yang terdiri dari abu vulkanik Merapi, pupuk kandang sapi dan tanah mineral memberikan pengaruh yang sangat nyata $\left(\begin{array}{ll}\alpha & .01\end{array}\right)$ terhadap kandungan $\mathrm{C}$ organik, asam humat-fulvat, berat volume dan bobot kering pupus tanaman jagung. Berbagai jenis bahan organik mampu memperbaiki sifat fisika, kimia dan biologi suatu media tanam (Lengkong dan Kawulusan, 2008). Fungsi utama bahan organik antara lain memperbaiki struktur tanah dan daya simpan air, memasok unsur hara dan asam-asam organik untuk melepaskan ikatan-ikatan material secara kimia, meningkatkan kapasitas tukar kation dan daya ikat hara, serta sebagai sumber karbon, mineral dan energi bagi mikroba (Syukur, 2005). 
Tabel 1. Pengaruh perlakuan pemberian abu vulkanis dan pupuk kompos terhadap beberapa sifat tanah

\begin{tabular}{cccccc}
\hline $\begin{array}{c}\text { Perlakuan/ } \\
\text { Pengamatan }\end{array}$ & $\begin{array}{c}\text { Berat Volume } \\
\left(\mathrm{g} / \mathrm{cm}^{3}\right)\end{array}$ & $\begin{array}{c}\text { C-organik } \\
(\%)\end{array}$ & $\begin{array}{c}\text { Kadar N total } \\
(\%)\end{array}$ & $\begin{array}{c}\text { Kadar P- } \\
\text { tersedia } \\
(\mathrm{ppm})\end{array}$ & $\begin{array}{c}\text { Kadar K - } \\
\text { tersedia } \\
(\mathrm{ppm})\end{array}$ \\
\hline A0 & $0,86 \mathrm{a}$ & $2,92 \mathrm{a}$ & $0,19 \mathrm{a}$ & $19,60 \mathrm{a}$ & $248,11 \mathrm{a}$ \\
A1 & $0,87 \mathrm{a}$ & $2,79 \mathrm{a}$ & $0,17 \mathrm{a}$ & $18,74 \mathrm{a}$ & $254,22 \mathrm{a}$ \\
A2 & $0,90 \mathrm{a}$ & $2,76 \mathrm{a}$ & $0,16 \mathrm{a}$ & $21,31 \mathrm{a}$ & $267,00 \mathrm{a}$ \\
BNT 5 \% & - & - & - & - & - \\
K0 & $0,91 \mathrm{~b}$ & $2,68 \mathrm{a}$ & $0,17 \mathrm{a}$ & $18,51 \mathrm{a}$ & $268,33 \mathrm{a}$ \\
K1 & $0,87 \mathrm{ab}$ & $2,76 \mathrm{a}$ & $0,17 \mathrm{a}$ & $20,11 \mathrm{a}$ & $242,67 \mathrm{a}$ \\
K2 & $0,85 \mathrm{a}$ & $3,05 \mathrm{~b}$ & $0,18 \mathrm{a}$ & $21,03 \mathrm{a}$ & $258,33 \mathrm{a}$ \\
BNT 5 \% & 0,05 & 0,35 & - & - & - \\
\hline
\end{tabular}

Analisis statistika menunjukkan bahwa pemberian abu vulkanis tidak berpengaruh nyata terhadap $\mathrm{N}$-total, kadar $\mathrm{P}$ tersedia tanah dan K-tersedia. Demikian juga pemberian pupuk kompos tidak berpengaruh nyata, hanya ada kecenderungan peningkatan dengan semakin meningkatnya pemberian kompos (Tabel 1). Hal ini mungkin disebabkan karena kandungan hara nitrogen, hara $\mathrm{P}$ dan K-tersedia yang berasal dari kompos jumlahnya kecil yaitu $\mathrm{N}=0,376 \%, \mathrm{~K}=$ 0,946 \%. Penelitian Irawan et al. (2016) meneliti tentang pemberian bahan organik terhadap sifat kimia tanah Andisol melaporkan bahwa pemberian pupuk kompos dan pupuk kandang tidak menyebabkan perubahan status $\mathrm{pH}, \mathrm{C}$ organik dan N-total, dan P-total, namun dapat meningkatkan status P-tersedia dan menurunkan P- retensi.

Pemberian abu vulkanis tidak menunjukkan pengaruh nyata terhadap tinggi tanaman, berat buah kering oven, berat biji kering oven dan berat brangkasan kering oven (Tabel 2). Pemberian abu vulkanis belum memberikan pengaruh yang nyata terhadap pertumbuhan dan hasil kacang tunggak. Hal ini mungkin disebabkan oleh abu vulkanis masih belum melapuk sehingga belum tersedia bagi tanaman kacang tunggak. Sutono et al. (2017) menyatakan abu vulkanik belum dapat menyumbangkan unsur hara bagi tanaman, karena merupakan bahan baru (recent material) yang belum mengalami pelapukan sempurna dan juga dominasi fraksi pasir. Penambahan bahan organic berupa pupuk kompos telah diberikan 


\section{WAYAN NARKA et al. Pengaruh Abu Vulkanis Gunung Agung dan Pupuk Kompos...}

sampai dosis 20 ton/ha dengan harapan bisa mempercepat pelapukan abu vulkanis, namun belum menunjukkan pengaruh yang signifikan terhadap tanah dan tanaman. Umur kacang tunggak sangat pendek sekitar 3 bulan. Mungkin dalam kurun waktu 3 bulan belum terjadi pelapukan bahan mineral yang berasal dari abu Gunung Agung.

Tampubolon (2018) juga menemukan hasil yang hampir sama yaitu pemberian abu vulkanis dan pupuk kandang kotoran sapi tidak berpengaruh nyata terhadap $\mathrm{pH}$ tanah, KTK tanah dan basa basa tertukar pada Tanah Ultisol. Namun pemberian pupuk kandang sapi berpengaruhnyata terhadap basa-basa-tertukar pada inkubasi 2 minggu dan 6 minggu. Interaksi antara kedua perlakuan ini tidak nyata terhadap semua parameter pengamatan selama penelitian. Tarigan et al. (2015) juga meneliti pemberian abu vulkanik dan bahan organic arang sekam padi terhadap tanaman bawang menemukan bahwa abu vulkanik dengan dosis $0,5,10,15$ ton/ha dan bahan organic arang sekam padi $0,10,20$ ton/ha tidak berpengaruh nyata terhadap semua parameter pangamatan. Beberapa hasil penelitian ini mengindikasikan bahwa perlu waktu cukup lama untuk terjadi pelapukan abu vulkanis sehingga tersedia bagi tanaman.

Tabel 2. Pengaruh pemberian abu vulkanis dan pupuk kompos terhadap tanaman kacang tunggak

\begin{tabular}{ccccc}
\hline $\begin{array}{c}\text { Perlakuan/ } \\
\text { Pengamatan }\end{array}$ & $\begin{array}{c}\text { Tinggi tanaman } \\
(\mathrm{cm})\end{array}$ & $\begin{array}{c}\text { Berat buah } \\
\text { kering oven }(\mathrm{g})\end{array}$ & $\begin{array}{c}\text { Berat biji kering } \\
\text { oven }(\mathrm{g})\end{array}$ & $\begin{array}{c}\text { Berat brangkasan } \\
\text { kering oven }(\mathrm{g})\end{array}$ \\
\hline A0 & $99,56 \mathrm{a}$ & $33,45 \mathrm{a}$ & $26,29 \mathrm{a}$ & $13,47 \mathrm{a}$ \\
A1 & $90,22 \mathrm{a}$ & $31,77 \mathrm{a}$ & $24,79 \mathrm{a}$ & $13,22 \mathrm{a}$ \\
A2 & $87,56 \mathrm{a}$ & $32,44 \mathrm{a}$ & $27,71 \mathrm{a}$ & $13,91 \mathrm{a}$ \\
BNT 5 \% & - & - & - & - \\
K0 & $74,00 \mathrm{a}$ & $24,63 \mathrm{a}$ & $19,54 \mathrm{a}$ & $11,69 \mathrm{a}$ \\
K1 & $93,56 \mathrm{ab}$ & $35,34 \mathrm{~b}$ & $28,84 \mathrm{~b}$ & $14,06 \mathrm{ab}$ \\
K2 & $109,78 \mathrm{~b}$ & $37,69 \mathrm{~b}$ & $30,40 \mathrm{~b}$ & $14,84 \mathrm{~b}$ \\
BNT 5\% & 28,82 & 3,97 & 3,49 & 2,76 \\
\hline
\end{tabular}

Pemberian pupuk kompos 0, 10 dan 20 ton/ha memberikan pengaruhnyata nyata terhadap tinggi tanaman, berat buah kering oven dan berat biji kering oven dan berat brangkasan kering oven (Tabel 2). Terjadi peningkatan dengan semakin meningkatnya dosis pupuk kompos. 
Berpengaruhnya pupuk kompos terhadap pertumbuhan dan hasil disebabkan karena pupuk kompos mengandung unsur hara N, P dan K. Kandungan hara N, P, K pada pupuk kompos yang dipakai adalah $\mathrm{N}$ $=0,376 \%, \mathrm{~K}=0,946 \%, \mathrm{C}$-organik $=12,85$ \%. Meningkatnya hara $\mathrm{N}, \mathrm{P}, \mathrm{K}$ di dalam tanah akan menyebabkan unsur makro ini menjadi lebih tersedia. Memang hasil analysis laboratorium kadar unsur hara $\mathrm{N}$, $\mathrm{P}, \mathrm{K}$ tidak signifikan akibat adanya perlakuan pupuk kompos, tetapi ada trend meningkat dengan meningkatkannya dosis pupuk kompos. Selain itu, pupuk kompos juga berpengaruh terhadap sifat fisik tanah, sifat biologi tanah dan sifat kimia tanah. Sifat fisik tanah, sifat biologi tanah dan sifat kimia tanah semakin baik akan mendorong terjadinya pertumbuhan tanaman lebih baik, dan selanjutnya berpengaruh terhadap hasil tanaman kacang tunggak. Lengkong dan Kawulusan (2008) menyatakan bahwa berbagai jenis bahan organik mampu memperbaiki sifat fisika, kimia dan biologi suatu media tanam. Selanjutnya Syukur (2005) menegaskan fungsi utama bahan organik antara lain memperbaiki struktur tanah dan daya simpan air, memasok unsur hara dan asamasam organik untuk melepaskan ikatanikatan material secara kimia, meningkatkan kapasitas tukar kation dan daya ikat hara, serta sebagai sumber karbon, mineral dan energi bagi mikroba.

Interaksi yang diharapkan dari abu vulkanis Gunung Agung dengan pupuk kompos dalam mempercepat tersedianya unsur hara di tanah yang selanjutnya berpengaruh terhadap tanaman belum ditemukan pada penelitian ini. Berdasarkan hasil analisis tanah, kadar $\mathrm{N}, \mathrm{P}, \mathrm{K}$ tidak berbeda nyata dengan adanya penambahan abu vulkanis dan pupuk kompos (Tabel 1). Hal ini terjadi mungkin disebabkan oleh waktu yang terlalu singkat yaitu hanya 3 bulan. Hasil penelitian ini hampir sama dengan hasil penelitian Tampubolon (2018) tentang pemberian abu vulkanis Merapi dan pupuk kandang kotoran sapi melaporkan bahwa interaksi antara kedua perlakuan ini tidak nyata terhadap semua parameter pengamatan selama penelitian. Tarigan et al. (2015) juga meneliti pemberian abu vulkanik dan bahan organic arang sekam padi terhadap tanaman bawang menemukan bahwa abu vulkanik dengan dosis $0,5,10$, 15 ton/ha dan bahan organic arang sekam padi $0,10,20$ ton/ha tidak berpengaruh nyata terhadap semua parameter pangamatan. Beberapa hasil penelitian ini mengindikasikan bahwa perlu waktu cukup lama untuk terjadi pelapukan abu vulkanis 


\section{WAYAN NARKA et al. Pengaruh Abu Vulkanis Gunung Agung dan Pupuk Kompos...}

sehingga tersedia bagi tanaman. Mungkin dengan bertambahnya waktu akan terjadi interaksi dalam pelapukan mineral yang ada pada abu vulkanis sehingga dapat meningkatkan ketersediaan unsure hara. Foy et al. (1978) mengatakan bahwa bahan organik bisa berpengaruh terhadap pelapukan bahan mineral abu vulkanis. Melalui pembentukan khelat logamorganik, asam-asam organik akan melarutkan mineral-mineral primer dan sekunder yang ada di dalam media tanam dan selanjutnya akan menjadi tersedia bagi tanaman. Makin besar afinitas kation logam terhadap asam humat- fulvat, maka semakin mudah terlepasnya kation dari permukaan berbagai jenis mineral. Asam humat-fulvat merupakan fraksi bahan organik yang mempunyai peranan penting dalam reaksi kimia di dalam tanah. Besarnya kandungan total asam humat- fulvat dalam bahan organik berkorelasi dengan besarnya kandungan lignin dan polifenol (Fox et al., 1990).

\section{SIMPULAN}

Berdasarkan hasil hasil penelitian ini dapat disimpulkan bahwa pemberian abu vulkanis Gunung Agung belum menunjukkan pengaruh nyata terhadap tanah dan tanaman kacang tunggak. Tidak ditemukan interaksi antara abu vulkanis dengan pupuk kompos terhadap ketersediaan hara dalam tanah. Pemberian pupuk kompos berpengaruh nyata terhadap pertumbuhan dan hasil kacang tunggak. Pemberian 20 ton pupuk kompos/ha dapat meningkatkan hasil kacang tunggak sebesar $55,57 \%$

\section{UCAPAN TERIMA KASIH}

Penulis mengucapkan terima kasih kepada Lembaga Penelitian dan Pengabdian kepada Masyarakat (LPPM) dan Dekan Fakultas Pertanian Universitas Udayana atas dukungan dana yang telah diberikan sehingga kegiatan penelitian ini dapat dilaksanakan dengan baik.

\section{DAFTAR PUSTAKA}

Anda, M., Kasno, A., \& Sarwani, M. (2012). Sifat dan Khasiat material letusan Gunung Merapi untuk Perbaikan Tanah Pertanian dalam Sutono, S., J Purnomo, J Purwani dan A Jamil. 2017. Berkah Abu Vulkanis Bahan Pembenah Tanah. Badan penelitian dan Pengembangan Pertanian. Kementerian Pertanian.

Clemens, D. F., Whitehurst, B. M. \& Whitehurst, G. B. (1990). Chelates in Agriculture. Fertilizer Research 25:127-131.

Fox, R. H., Myers, R. J. K., \& Vallis, I. (1990). The nitrogen mineralization rate of legume residues in soils as influenced by their polyphenol, 
lignin and nitrogen contents. Plant Soil, 129: 251-259.

Foy, C. D., Chaney, R. L., \& White, M. C. (1978). The physiology of metal toxity in plants. Ann. Rev. Plant Physiol, 29:511-566

Hasanah, Y., Esther, T., \& Mariati. (2015). Respons Pertumbuhan dan Produksi Bawang Merah (Allium ascalonicum L.) terhadap Pemberian Abu Vulkanik Gunung Sinabung dan Arang Sekam Padi. Jurnal Online Agroekoteknologi, Vol.3 (3): 956962.

Irawan, A., Jupri, Y., \& Zuraida. (2016). Pengaruh Pemberian Bahan Organik Terhadap Perubahan Sifat Kimia Andisol, Pertumbuhan dan Produksi Gandum (Triticum eastivum L.). Jurnal Kawista 1(1):1-9

Kompas.

https://sains.kompas.com/read/2017/

10/06/070900223/letusan-gunungagung-bisa-menghasilkan-tanahtersubur-di-dunia?page $=$ all

Lawenga, F. F., Hasanah, U., \&. Widjajanto, D. (2015). Pengaruh Pemberian Pupuk Organik terhadap Sifat Fisika Tanah dan Hasil Tanaman Tomat (Lycopersicum esculentum Mill) di Desa Bulupountu Kecamatan Sigi Biromaru Kabupaten Sigi. E-J. Agrotekbis 3 (5): 564-570.

Lengkong, J. E., \& Kawulusan, R. I. (2008). Pengelolaan Bahan Organik Untuk Memelihara Kesuburan Tanah. J. Soil Environment. 6 (2): 91-97

Nurlaeny, N., Saribun, D. S., \& Hudaya, R. (2012). Pengaruh Kombinasi Abu Vulkanik Merapi, Pupuk Organik dan Tanah Mineral terhadap Sifat Fisiko-Kimia Media Tanam serta Pertumbuhan Tanaman Jagung (Zea mays L.). Bionatura- Jurnal Ilmu- ilmu Hayati dan Fisik, Vol. 14.(3), 184-191.

Sutono, S., Purnomo, Purwani, J., \& Jamil, A. (2017). Berkah Abu Vulkanis Bahan Pembenah tanah. Badan Penelitian dan Pengembangan Pertanian. Kementerian Pertanian

Syukur, A. (2005). Pengaruh Pemberian Bahan Organik terhadap Sifat-sifat Tanah dan Pertumbuhan Caisim di Tanah Pasir Pantai. J. Ilmu Tanah dan Lingkungan. 5 (1): 30-38.

Tampubolon, W. N. S. (2018). Pengaruh pemberian Abu Vulkanis dan Pupuk Kandang terhadap $\mathrm{pH}$, KTK dan Basa-basa Tertukar Tanah Ultisol. Skripsi. Program Studi Agroekoteknologi, Jurusan Budidaya Fakultas Pertanian Universitas Sriwijaya. $40 \mathrm{~h}$

Tarigan, E., Hasanah, Y., \& Mariati. (2015). Respon Pertumbuhan dan Produksi Bawang Merah (Allium ascalonicum L.) terhadap Pemberian Abu Vulkanik Gunung Sinabung dan Arang sekam Padi. Jurnal online Agroekoteknologi Vol. 3 (3) : 956962 